\title{
Fertility transitions in Kenya and Ghana: Trends, determinants and implications for policy and programs
}

\author{
Ian Askew \\ Population Council \\ Baker Ndugga Maggwa \\ Population Council \\ Francis Onyango \\ Population Council
}

Follow this and additional works at: https://knowledgecommons.popcouncil.org/departments_sbsr-rh

Part of the International Public Health Commons, Maternal and Child Health Commons, Obstetrics and Gynecology Commons, Social and Behavioral Sciences Commons, and the Women's Health Commons

How does access to this work benefit you? Let us know!

\section{Recommended Citation}

Askew, lan, Baker Ndugga Maggwa, and Francis Onyango. 2015. "Fertility transitions in Kenya and Ghana: Trends, determinants and implications for policy and programs," presentation, Workshop on Recent Trends in Fertility in Sub-Saharan Africa, Washington, DC. 


\section{Fertility transitions in Kenya and Ghana: Trends, Determinants and Implications for Policy and Programs}

Ian Askew, Population Council Ndugga Maggwa, Bill and Melinda Gates Foundation Francis Onyango, Population Council

National Research Council Committee on Population Workshop on Recent Trends in Fertility in Sub-Saharan Africa June 15-16, 2015 National Academy of Science, Washington, DC 


\section{Why Focus on Kenya and Ghana}

$\checkmark$ First countries to develop and launch population policies in Sub-Saharan Africa

$\checkmark$ Have developed and implemented a wide range of policies and programs aimed at increasing availability of family planning

$\checkmark$ Both have experienced significant changes in TFR and CPR since 1970

$\checkmark$ Represent different social and economic contexts 


\section{Sources of Data}

- DHS datasets for 1993 - 2014 (some variables only for 2008)

- PMA 2020 survey results for 2014

- Review of documents describing national policies, strategies and implementation plans

- Authors' personal experience of working with family planning programs in both countries

- Discussions with country program managers and implementation partners 


\section{Factors considered in our analysis}

- Reproductive behavior of individual women or couples as indicated by changes in their fertility preferences and/or contraceptive behaviors

- Socio-economic and demographic characteristics of sub-populations

- Institutional factors, including shifts in policy and/or service delivery environments 


\section{Fertility trends:}

\section{Rapid decline; Stall and plateau; Recent changes}

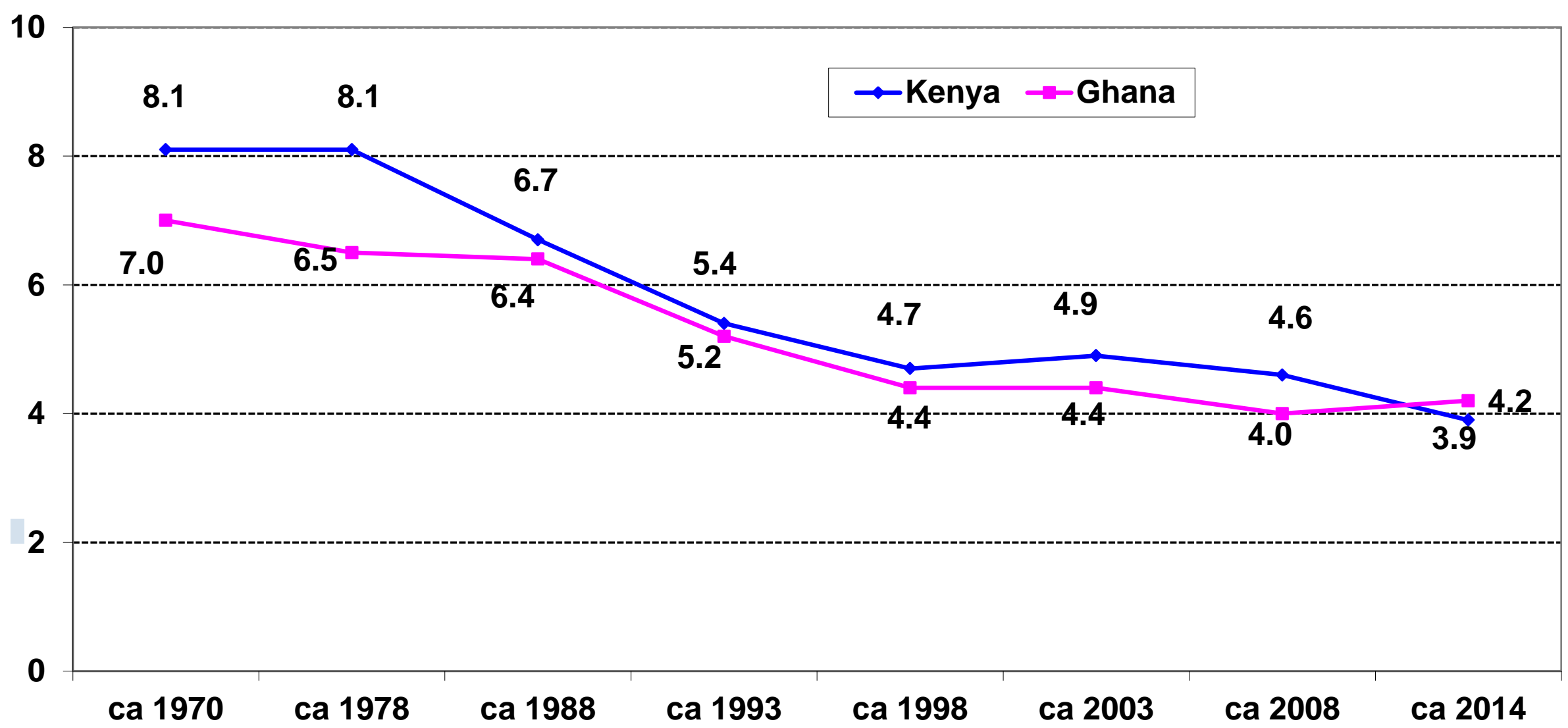




\section{Fertility trends by sub-population}

- Wealth:

$>$ Richest used to be most different

$>$ Poorest quintile now significantly higher

- Education:

$>$ Uneducated now $3.5-4.0$ births higher than most educated 


\section{Fertility trends by place of residence:}

Nationwide increase in Ghana

Rural decline, urban increase in Kenya

Ghana 1988-2014

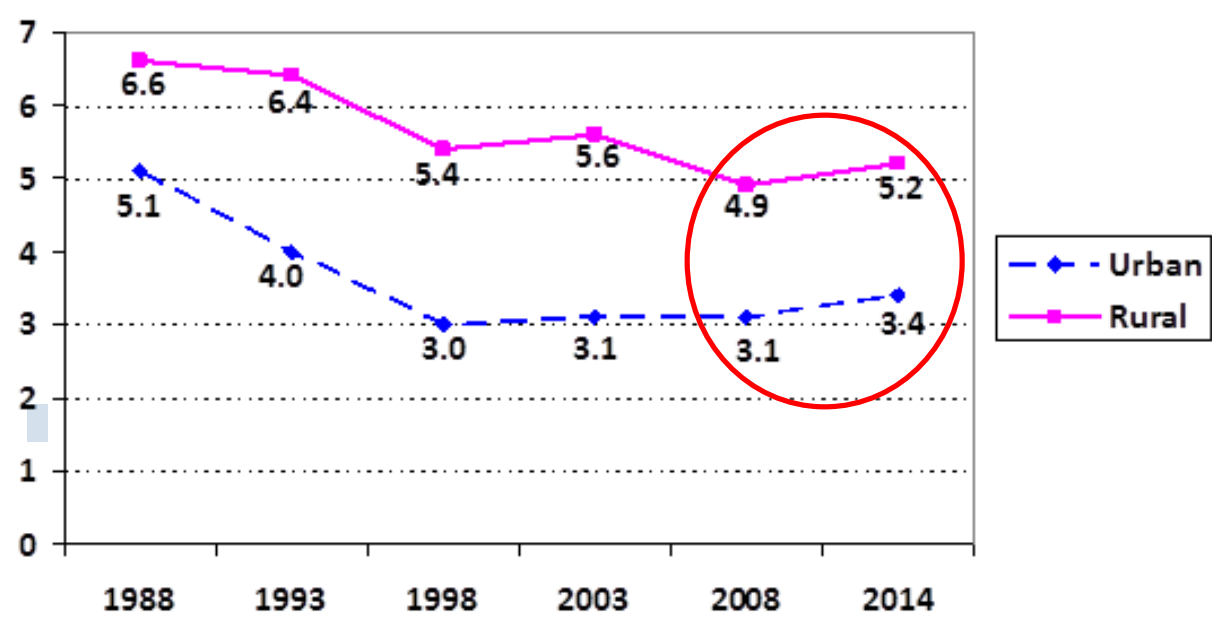

Kenya 1989-2014

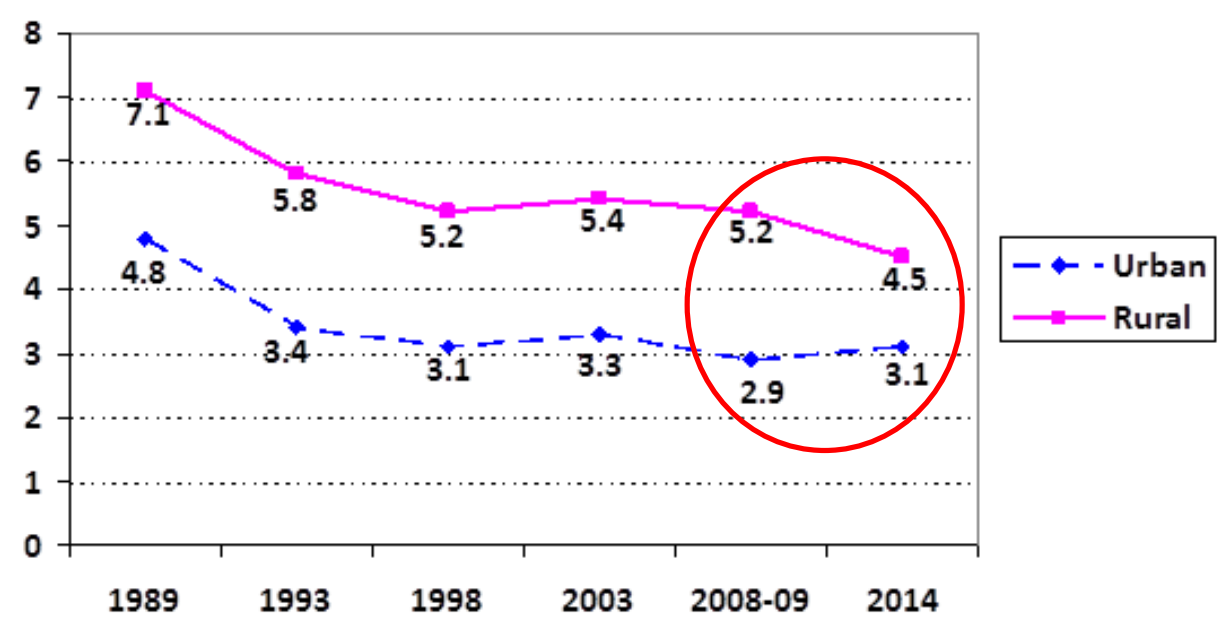




\section{Fertility trends among $15-19$ year olds}

\section{Urban-rural differences increased Huge differences by education}
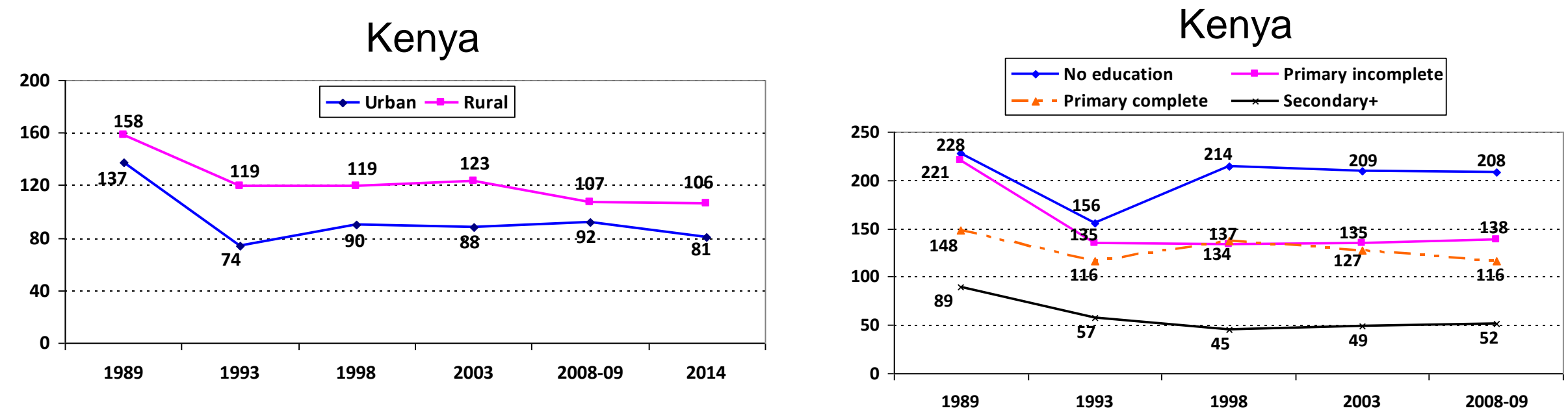

\section{Ghana}

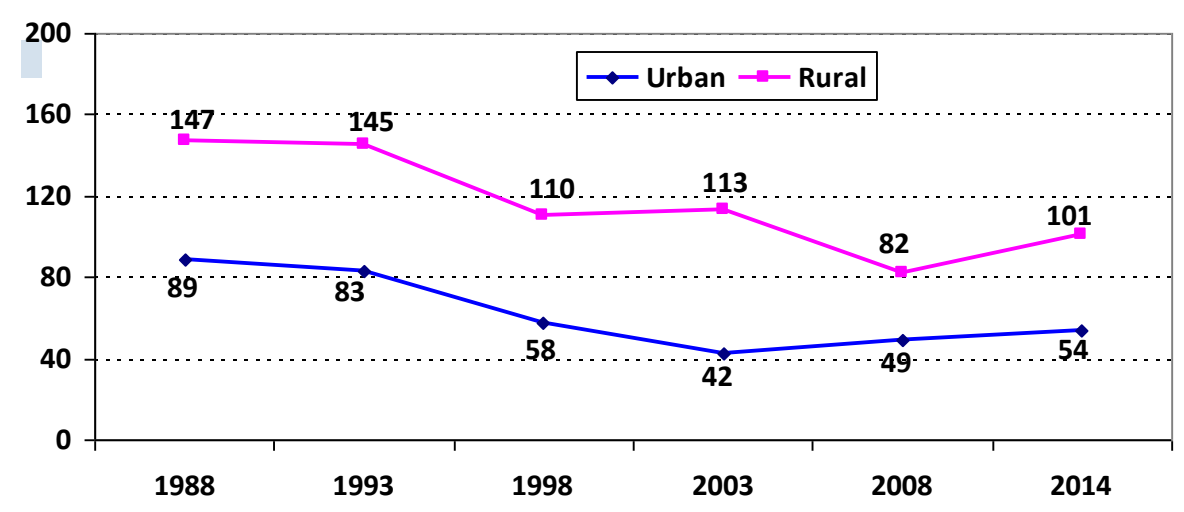

Ghana

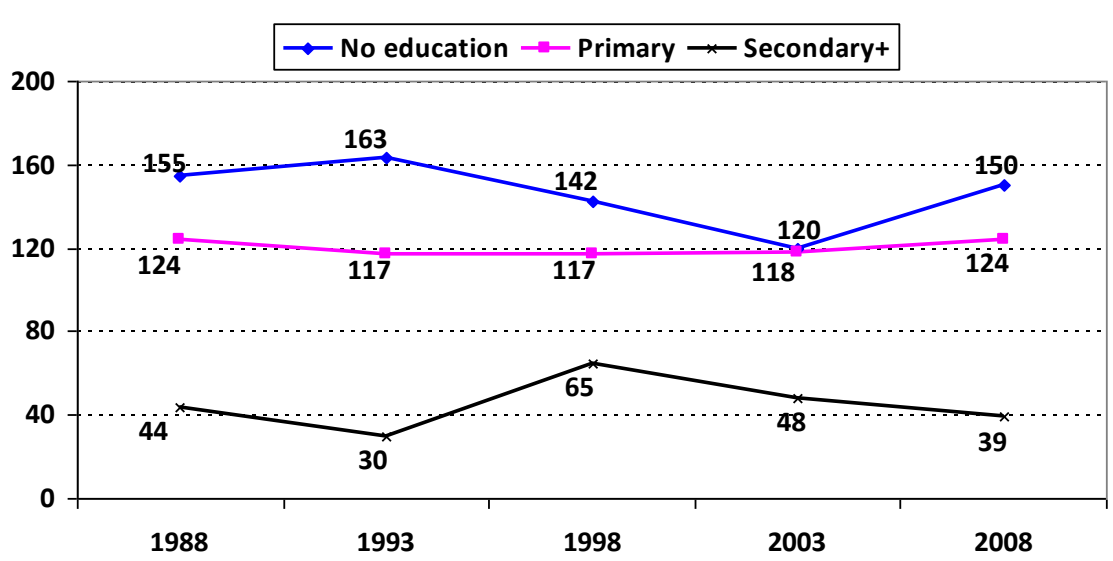




\section{Wanted Fertility Rates and Desired Family Size have plateaued in both countries}
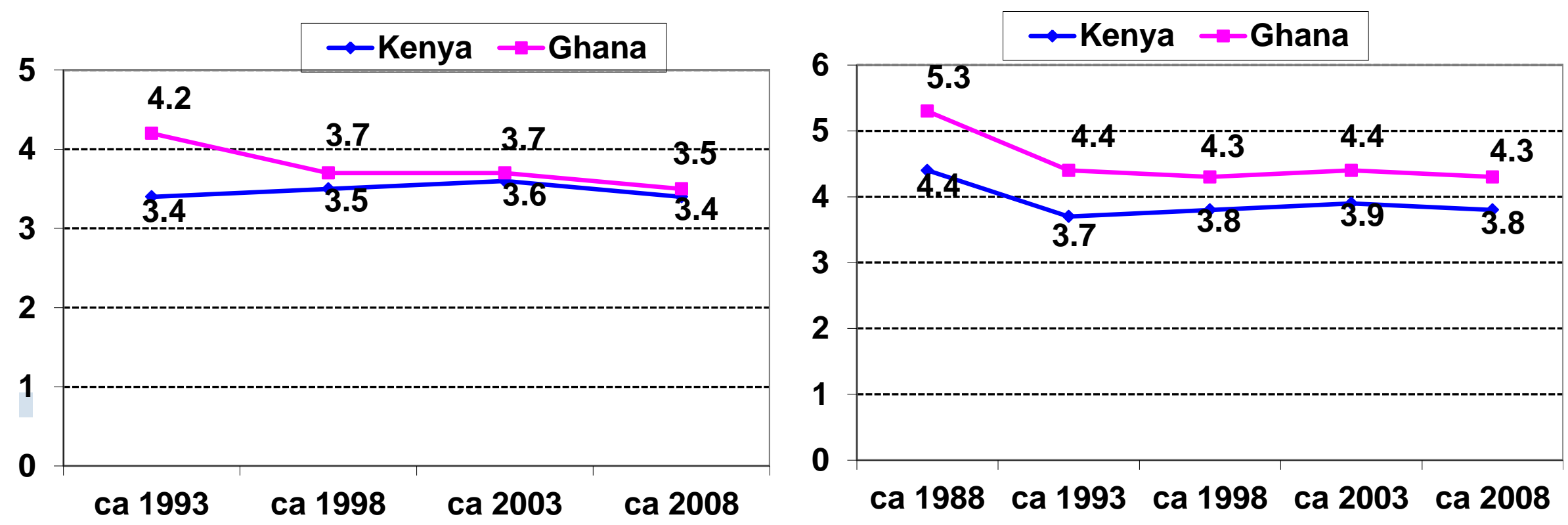


\section{Unwanted fertility rates:}

Have also plateaued over time, but at much lower rates in Ghana

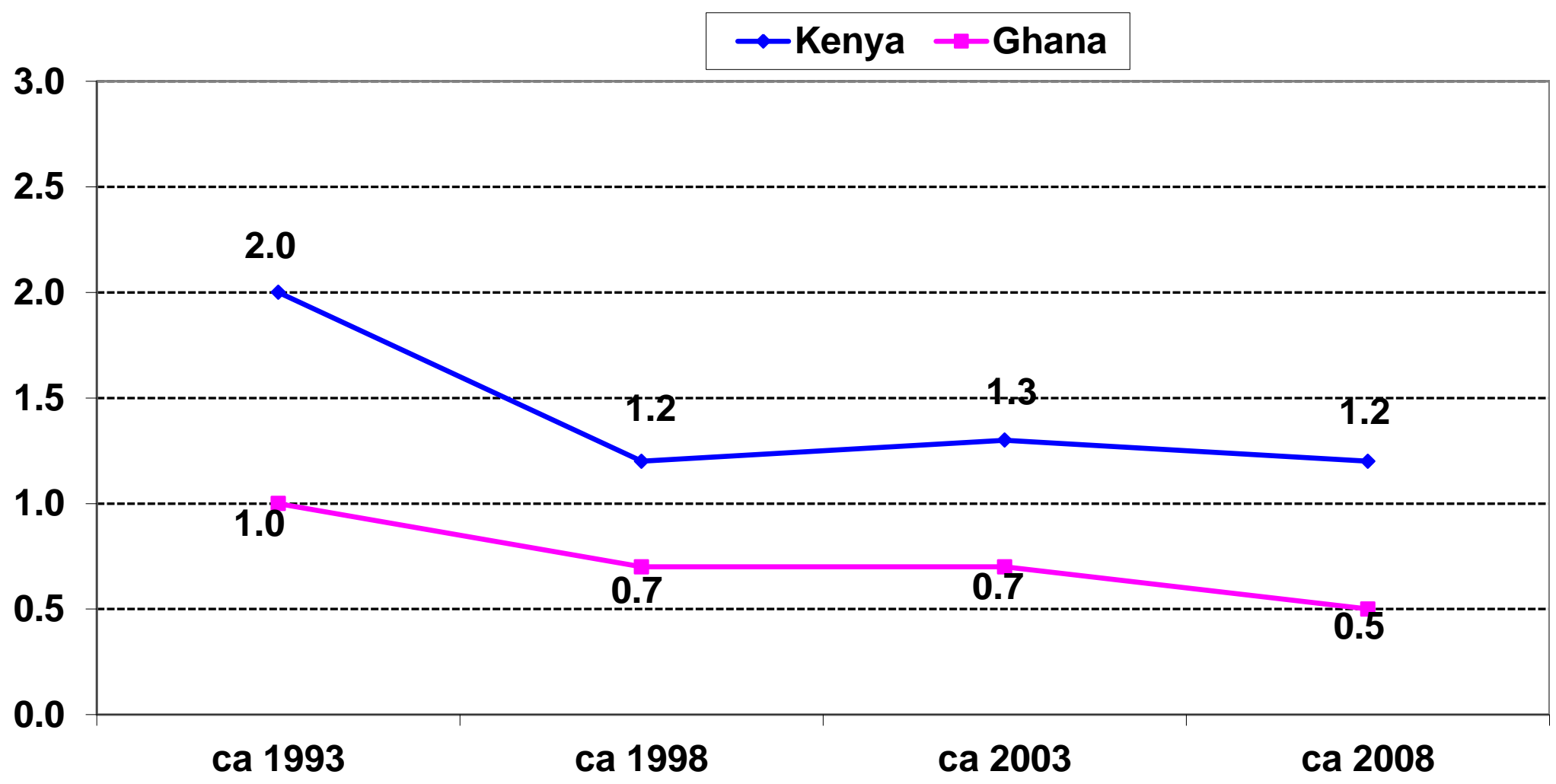




\section{National responses: multiple policies and programs Kenya}

- 1965: Population issues first highlighted in Sessional Paper

- 1967: Government adopted official population policy and established a national family planning action programme under the Ministry of Health, with an emphasis on reduction of family size and spacing of children to reduce population growth rate

- 1982: Government established National Council for Population and Development (NCPD) in the Office of the Vice President and Ministry of Home Affairs. Role and mandate contained in 1984 Sessional Paper No. 4 on Population Policy Guidelines

- 1994: 'Manage population growth' a strategic imperative Kenya Health Policy Framework and reiterated in NHSSP I and II

- 1996: NCPD publishes National Population Advocacy and IEC Strategy for Sustainable Development (until 2010)

- 1997: National Reproductive Health Strategy (1997-2010) launched

- 2000: Sessional Paper No. 1 on second National Population Policy for Sustainable Development (NPPSD)

- 2003: Adolescent Reproductive Health and Development policy

- 2004: National Coordinating Agency for Population and Development replaces NCPD

- 2005/6: Parliamentary budget allocates Government funds to family planning for the first time

- 2007: National Reproductive Health Policy published

- 2007: Population growth, and especially urban and young, mentioned in Vision 2030 document

\section{Ghana}

- Ghana Population Policy (1969)

- National Population Policy (Revised 1994)

- Ghana Vision 2020 (1995)

- National Reproductive Health Service Policy and Standards (1996)

- Adolescent Reproductive Health Policy (1996)

- Roadmap for Repositioning Family Planning in Ghana (2006-2010)

- National Health Policy (2007)

- National Reproductive Health Policy and Service Standards (Revised 2003)

- National Reproductive Health and Commodity Security Strategy (2011-2016)

- MDG Acceleration Framework for MDG 5 (2012) Prioritized Acceleration Solution: Develop proposal and mobilize the international community to ensure adequate funding for the procurement of commodities

- Ghana Shared Growth and Development Agenda (20102013) 


\section{All-method contraceptive use among married women in each country shows different trends.... and is not reflected the unwanted fertility trends}

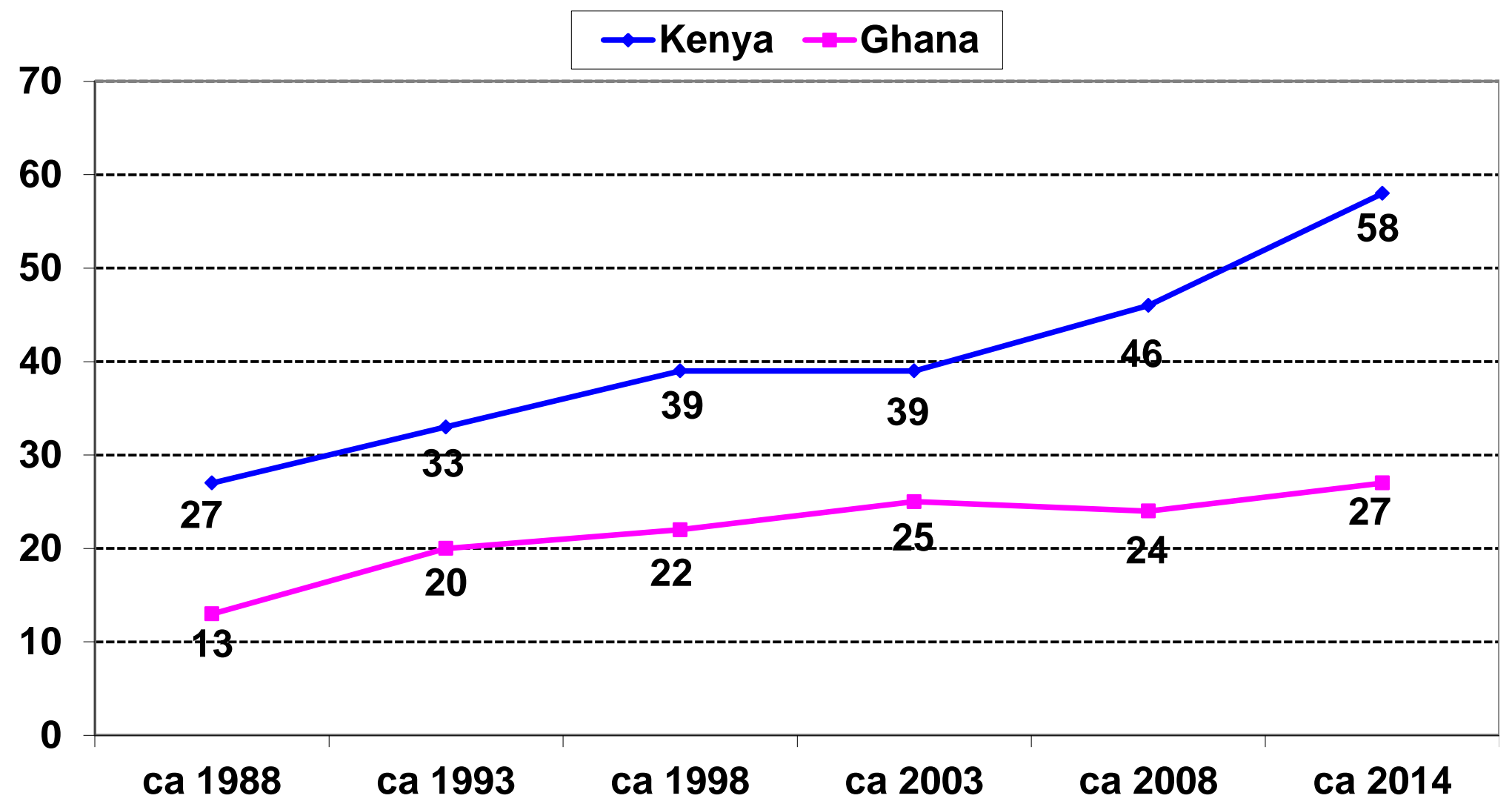




\section{Among currently married women in Kenya, the gap in modern contraceptive use has increased among uneducated and poorest}

Education
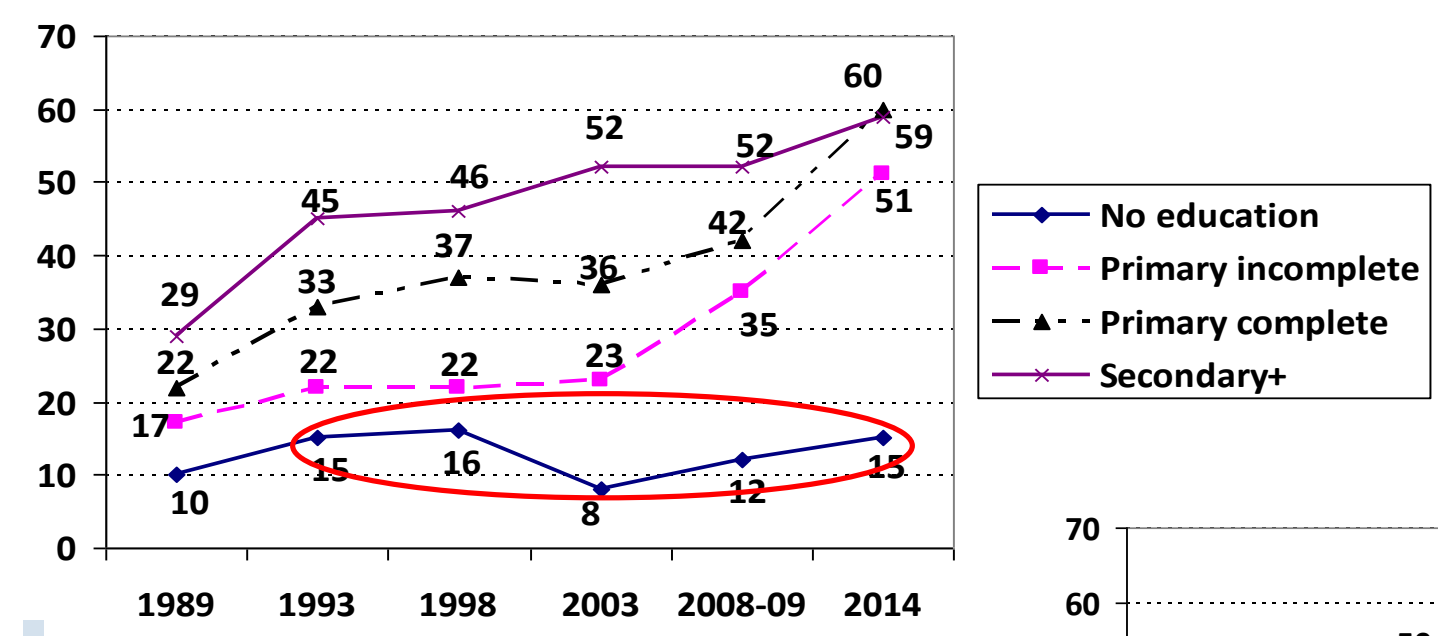

Wealth

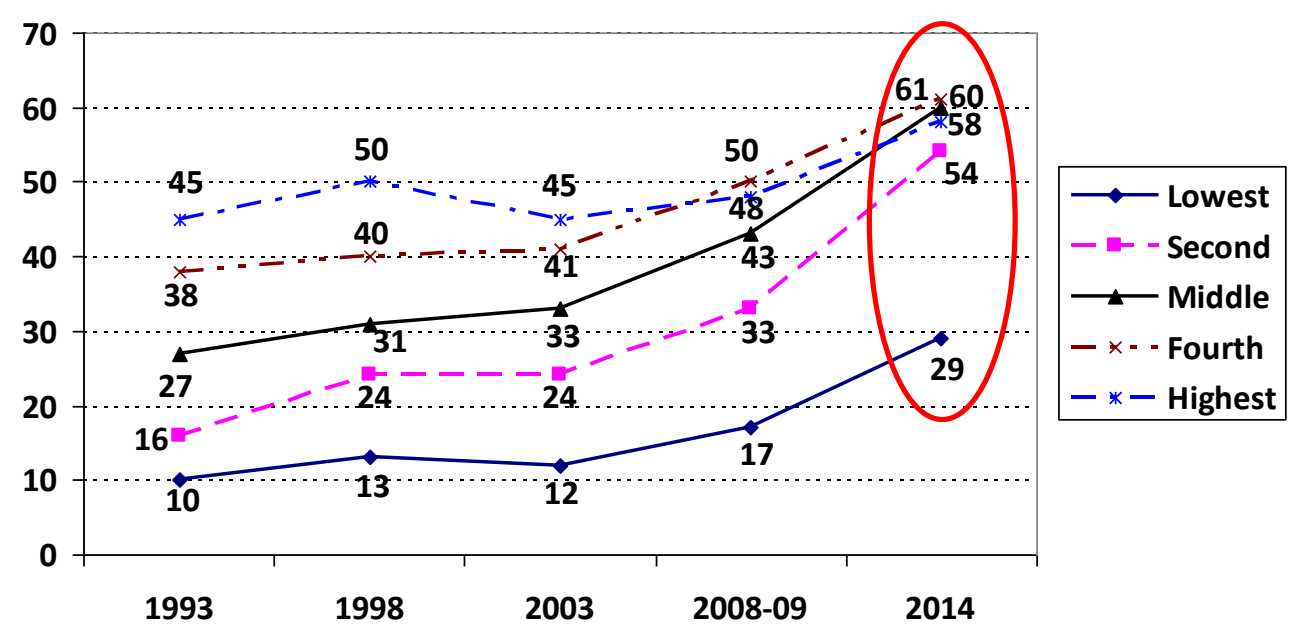




\section{Use of modern methods among currently married women has increased more in rural than in urban populations in both countries}

Ghana $1988-2014$

$$
\rightarrow \text { Urban }+ \text { Rural }
$$

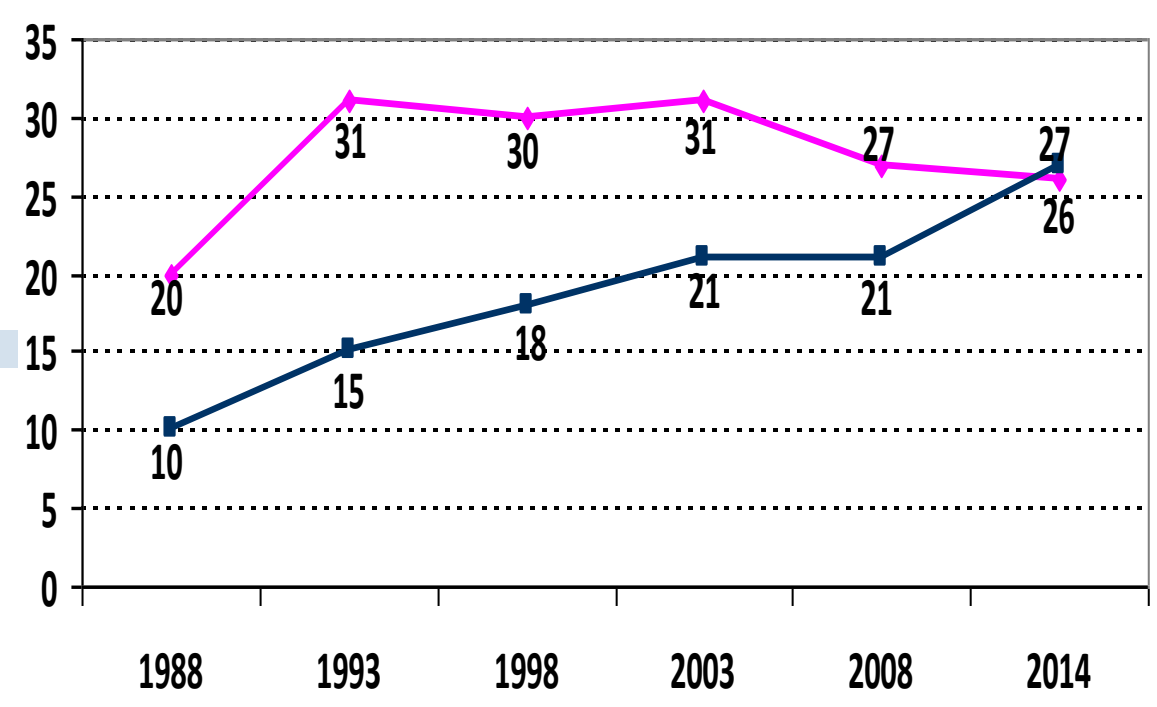

Kenya $1989-2014$

$\rightarrow$ Urban $\rightarrow$ Rural

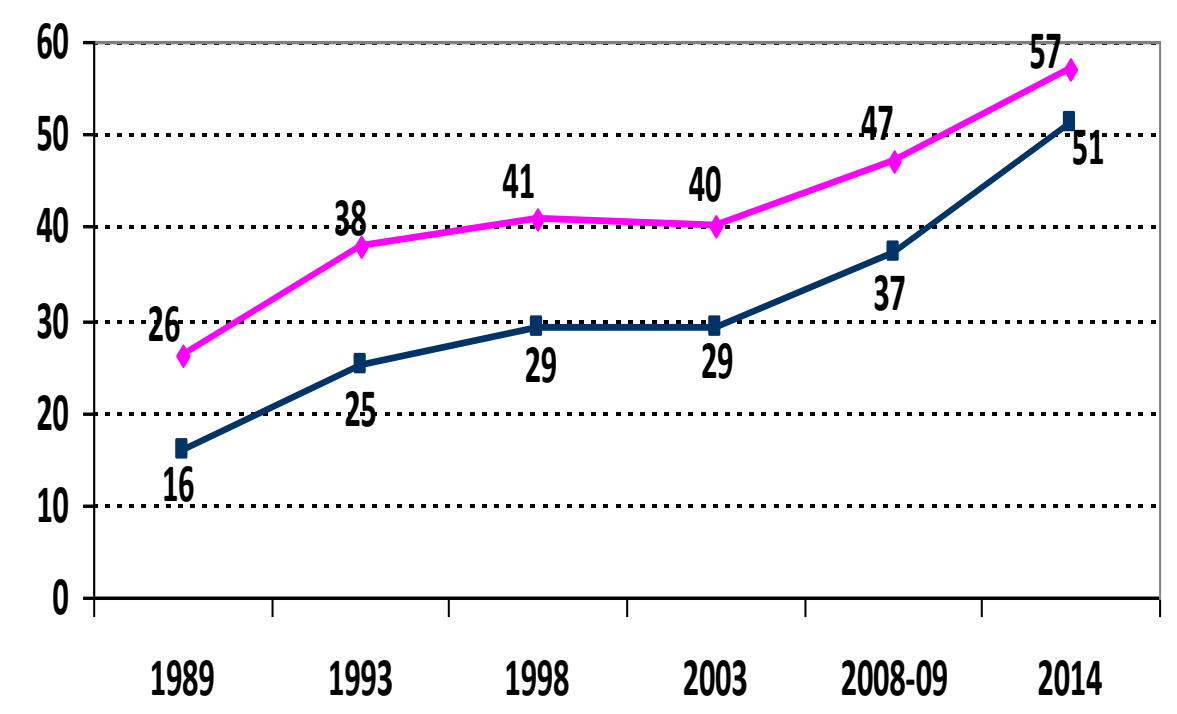




\section{Moreover, in Ghana modern method use has stalled among educated and wealthy women}
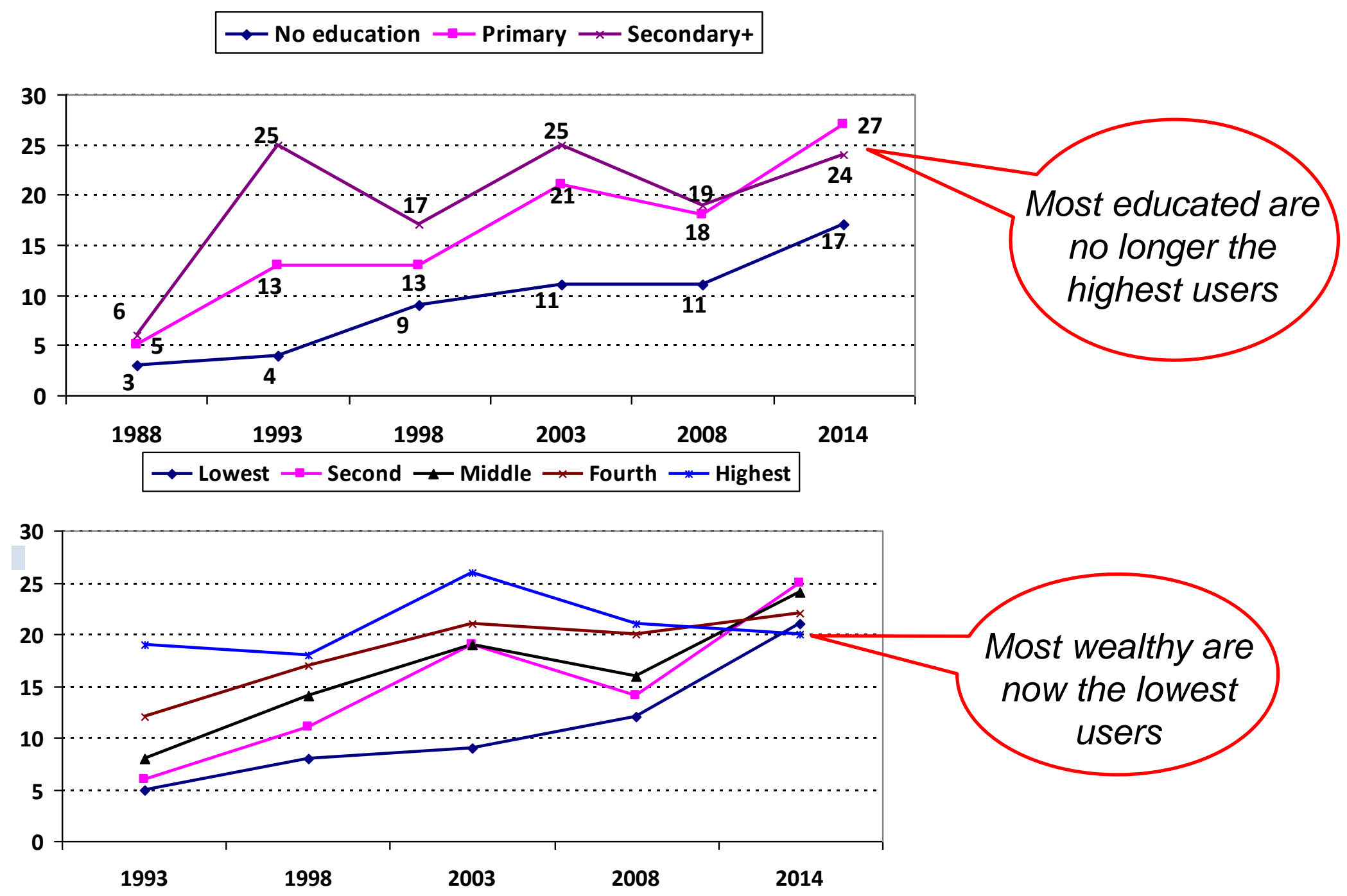


\section{Unmet need has decreased rapidly over past five years in both countries}

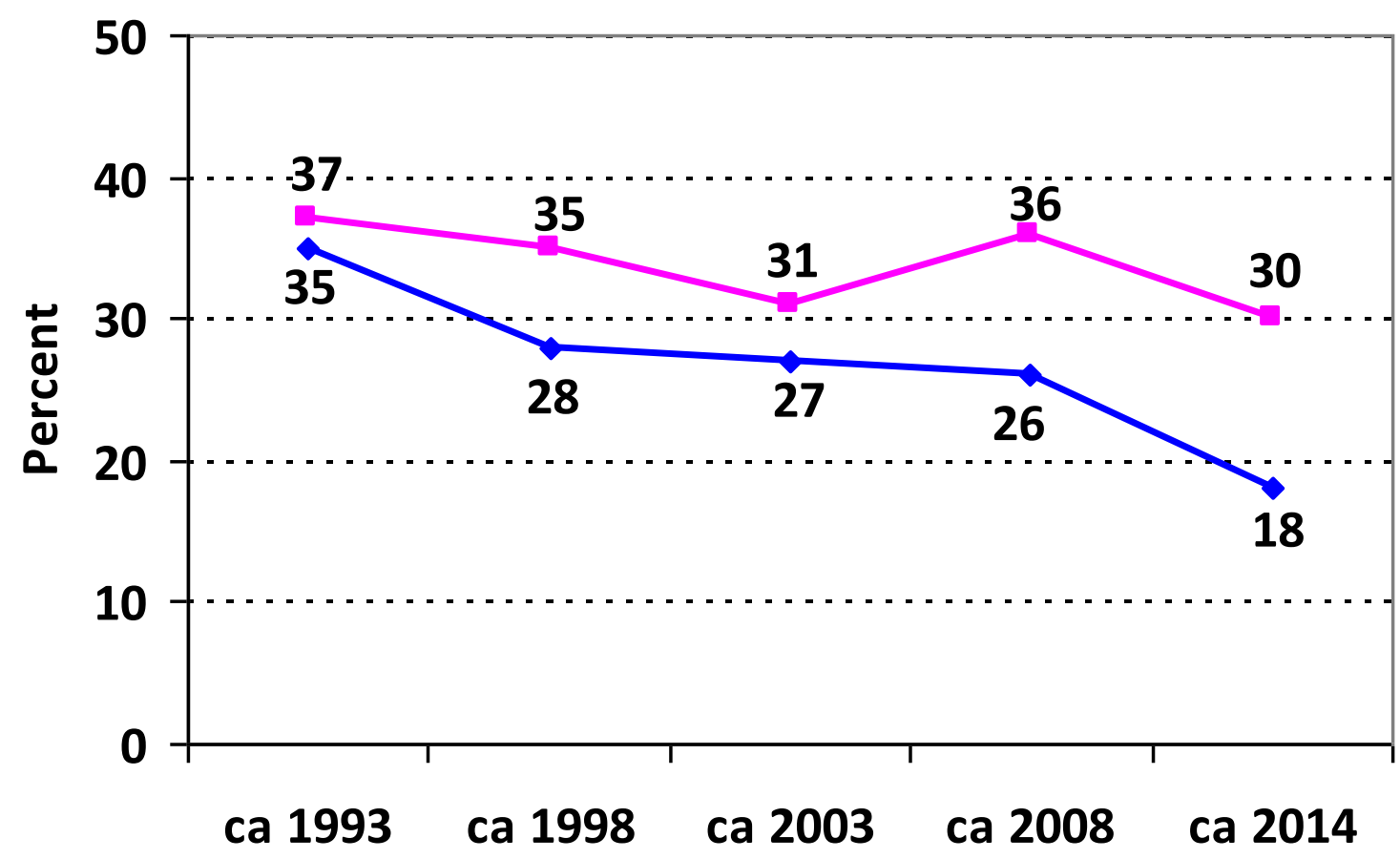

$$
\begin{aligned}
& \rightarrow \text { Kenya } \\
& \rightarrow \text { Ghana }
\end{aligned}
$$




\section{Conclusions and Recommendations: Behavioral Factors}

- Both countries have experienced similar trends in TFR, despite differences in contraceptive use levels and patterns

- Age at first sex and marriage has increased in both countries but still long duration of non-use among sexually active unmarried

- But women initiating contraception late; e.g. 5.8 and 2.8 years after first sex and marriage in Ghana

- Both countries have seen a rapid increase in contraceptive use among married $15-19$ years and rural populations

- Ghana has lower wanted and unwanted fertility rates

- Although this may change when 2014 data are available 


\section{Conclusions and Recommendations: Socio-economic and demographic characteristics factors}

- Poor, uneducated and rural Kenyan women have much higher TFR (including wanted TFR), unmet need and lowest contraceptive use

- TFR and mCPR have stalled among urban, educated and wealthiest in Ghana

- In Ghana contraceptive use has increased among rural women, surpassing that among urban women

- Both countries have distinct socio-geographic areas with extremely high TFR, high DSF and low CPR 


\section{Conclusions and Recommendations: Policy and Structural factors}

- Both countries have developed supportive policies and implemented a wide range of strategies

- Both still rely on donors resources to fund implementation of their strategies

- Major gaps in funding exist, hampering full implementation

- Method mix still limited and majority of new users rely on DMPA, which has challenges with discontinuation and potential ineligibility for women at risk of HIV acquisition

- The Kenyan program is not meeting the needs of rural, poor and uneducated women

- The Ghanaian program is not meeting the needs of urban, wealthy and educated women 